\title{
METOdOLOGIA PARA ELABORAÇÃO DE FERMENTADO DE CAJÁ (Spondias mombin L.) ${ }^{1}$
}

\author{
Disney Ribeiro DIAS ${ }^{4}$, Rosane Freitas SCHWAN ${ }^{2, *}$, Luiz Carlos Oliveira LIMA ${ }^{3}$
}

\begin{abstract}
RESUMO
Os objetivos deste trabalho foram a elaboração de um processo de fermentação a partir do mosto de polpa de cajá, Spondias mombin para a obtenção de uma bebida alcoólica, bem como a avaliação da aceitação da mesma. As polpas das frutas utilizadas foram quimicamente analisadas (açúcares, acidez, pectina, vitamina C, pectinases, amido e fenólicos). A polpa de cajá foi chaptalizada a $24^{\circ}$ Brix, constituindo 20L de mosto. O mosto foi desacidificado, com $\mathrm{CaCO}_{3}$, a pH 3,8, para ser submetido ao tratamento enzimático com Ultrazym ${ }^{\mathrm{R}}$ AFP-L (Novo DK). Foi utilizado $\mathrm{SO}_{2}$ como agente inibidor do crescimento bacteriano e como antioxidante. O mosto foi clarificado com bentonite. Posteriormente, o mosto foi inoculado com Saccharomyces cerevisiae tipo selvagem na concentração de $10^{7}$ células $/ \mathrm{mL}$. A fermentação foi conduzida a $22^{\circ} \mathrm{C}$ durante 10 dias, com acompanhamento diário do grau Brix e da atividade fermentativa pela liberação de $\mathrm{CO}_{2}$. Ao final da fermentação, o mosto foi armazenado a $10^{\circ} \mathrm{C}$ por 10 dias e foi feita a primeira trasfega. A segunda trasfega ocorreu 30 dias após a primeira, antes da filtração. Na bebida elaborada foram feitas análises de etanol, glicerol, ácidos orgânicos, álcoois superiores, metanol, ésteres e acetaldeído. Observou-se alta concentração de álcoois superiores, os quais são normalmente responsáveis pela formação do sabor e aroma em bebidas alcóolicas. A aceitação da bebida foi avaliada por 45 provadores não treinados, utilizando-se escala hedônica de 9 pontos. Os dados mostraram que o fermentado de cajá foi bem aceito, podendo ser uma nova fonte de investimento para indústrias ou pequenos produtores.

Palavras-chave: fermentação alcoólica; Saccharomyces cerevisiae; Spondias mombin; cajá; bebida fermentada; fruticultura.
\end{abstract}

\section{SUMMARY}

METHODOLOGY FOR ELABORATION OF FERMENTED ALCOHOLIC BEVERAGE FROM YELLOW MOMBIN (Spondias mombin). The aim of this work was to define the methodology to produce and evaluate the acceptance of alcoholic beverage made from yellow mombin (Spondias mombin) fruit pulp. The fruit pulp used was chemically characterised (sugars, acidity, pectin, vitamin C, pectinases, starch and phenols). The yellow mombin fruit pulp had its sugar content adjusted to $24^{\circ}$ Brix with a sucrose solution. The must was deacidified using $\mathrm{CaCO}_{3}$ until it reached $\mathrm{pH}$ value of 3.8 and then enzymatically treated with Ultrazym AFP-L (Novo DK). Sulphur dioxide, as potassium metabissulfite, was used as an inhibitor of bacterial growth and as an antioxidant. Bentonite was also added to aid the must clarification. After these adjustments the must was inoculated with $10^{7} \mathrm{cell} / \mathrm{ml}$ of Saccharomyces cerevisiae wild type strain. The fermentation was carried out at $22^{\circ} \mathrm{C}$ for 10 days, with daily monitoring of Brix and fermentation activity by the liberation of $\mathrm{CO}_{2}$. At the end of the fermentation, the fermented must was stored at $10^{\circ} \mathrm{C}$ for 10 days and a first separation of the yeasts and solids particles was done. The second separation was done 30 days later, before the filtration. Ethanol, glycerol, organic acids, higher alcohols, methanol, esters and acetaldehyde were analysed in the final product. There was a high concentration of higher alcohols, which are usually responsible for the flavour found in alcoholic beverages. The acceptance of the drink was tested with 45 non-experienced panellists using the hedonic scale (1-9). The beverage was well accepted and might be a good investiment for small or medium companies.

Keywords: alcoholic fermentation; Saccharomyces cerevisiae; Spondias mombin; cajá; alcoholic beverage; fruit growing.

\section{1 - INTRODUÇÃO}

A produção do vinho passou de somente arte para arte com embasamento científico, ampliando-se as pesquisas em vitivinicultura [12]. Toda a tecnologia de produção do vinho é conhecida e cada vez mais estudada, buscando-se a melhor qualidade e a maior produtividade [37]. A vitivinicultura tem sido difundida no Brasil com vistas a um crescimento de produção e valorização do vinho nacional. Como a uva, várias outras frutas podem ser utilizadas para a formulação de mostos que podem, posteriormente, ser submetidos à fermentação alcoólica por ação de leveduras. Entretanto, não há tecnologia totalmente voltada para a elaboração destas be-

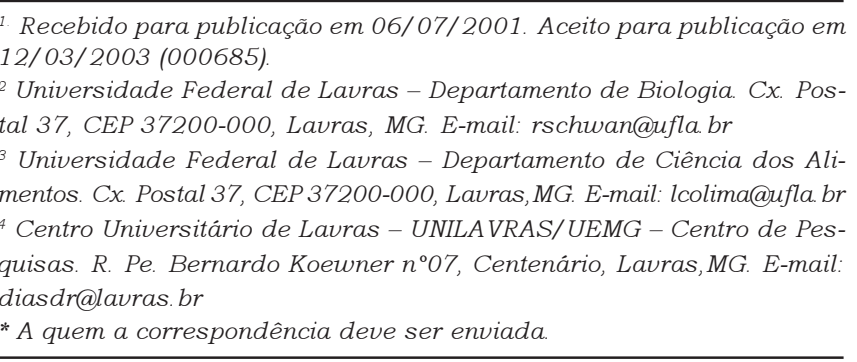

bidas no que se diz respeito à levedura a ser utilizada, a temperatura ideal de fermentação, o tipo de tratamento que o mosto da fruta, ou a própria fruta, deve sofrer na fase pré-fermentativa.

O Brasil é um dos países com maior produção mundial de frutas, incluindo a fruticultura tropical. Entretanto, há um grande desperdício pós-colheita para algumas culturas, o que, notadamente, gera prejuizos. Existe portanto a necessidade de se desenvolver novos processamentos que permitam a redução das perdas e proporcionem um incremento na renda do agricultor. Uma das alternativas para que isto ocorra é a produção de bebida alcoólica a partir de frutas nativas ou daquelas que facilmente se propaguem no solo brasileiro.

O cajá, Spondias mombin, é uma fruta cuja industrialização está voltada para a produção de polpas. JOAS [23], menciona que a polpa de cajá pode ser usada no preparo de bebidas levemente ácidas com agradável sabor, o qual é muito apreciado pelos europeus. GOMES [17] descreve o fruto da cajazeira como sendo saboroso e refrescante, apropriado para a produção de geléias, compotas, refrescos e sorvetes. Do suco se faz boa aguardente e um licor delicado. Cita, ainda, que a cajazeira é 
uma frutifera com potencial para a agroindústria, mas é subestimada e merece um investimento maior na sua utilização.

ARKCOLL [3], num estudo sobre perspectiva de espécimes vegetais brasileiras, em especial as amazônicas (tropicais) com possivel viabilidade comercial, cita, entre outras, o cajá, Spondias mombin, o cupuaçu, Theobroma grandiflorum, a graviola, Annona muricata, e o araçá-boi, Eugenia stipitata. O cajá ou taperebá é uma das mais populares frutas das regiões Norte e Nordeste do Brasil, gerando ótimos sucos e sorvetes [1, 30].

A elaboração de uma metodologia para obtenção de bebida alcoólica fermentada a partir da polpa de cajá (fermentado de cajá), bem como as análises quimicas na bebida e a avaliação da aceitação da mesma junto a provadores, foram os objetivos deste trabalho.

\section{2 - MATERIAL E MÉTODOS}

\section{1 - Amostragem das polpas}

Os frutos de cajá utilizados neste trabalho foram colhidos em vários municipios das regiões Norte e Nordeste e processados no CEPEC/CEPLAC (Centro de Pesquisa do Cacau/Comissão Executiva do Plano da Lavoura Cacaueira), Itabuna, BA, sendo também caracterizados quimicamente. Algumas análises foram feitas no fruto, como peso (total, relação casca/polpa e semente). As polpas foram extraídas por meio de uma despolpadeira automática (ITAMETAL 0.5 DS, Itabuna-BA). Uma amostra das polpas foi retirada para a caracterização química da mesma. Foram determinados sólidos solúveis [4], açúcares totais [46], açúcares redutores [28], amido [4], acidez total titulável [21], pH [21], vitamina C [43], pectinas [27], fenólicos [36], atividades de pectinametilesterase [22], peroxidase [26], polifenoloxidase [45] e poligalacturonase [35]. As polpas foram embaladas em sacos plásticos com capacidade para $0,5 \mathrm{~L}$ e $1,0 \mathrm{~L}$ e congeladas a $-20^{\circ} \mathrm{C}$ sem aditivo químico. As polpas, congeladas e acondicionadas em caixas isotérmicas foram enviadas por via aérea até Belo Horizonte, de onde foram encaminhadas para Lavras por transporte rodoviário. Foram estocadas a $-20^{\circ} \mathrm{C}$. Para a preparação do mosto, as polpas foram descongeladas, por $24 \mathrm{~h}$, à temperatura ambiente $\left(\sim 25^{\circ} \mathrm{C}\right)$.

\section{2 - Mosto: preparo e correções}

Para o preparo do mosto, um volume de polpa foi transferido para uma dorna fermentativa, de aço inox, com 30L de capacidade. Para a adequação da metodologia, foram feitas fermentações prévias em volumes de 5L e 10L. Após as análises, realizadas em triplicata, foram feitas as fermentações de $20 \mathrm{~L}$ de mosto, as quais renderam cerca de $12 \mathrm{~L}$ de bebida cada uma.

\subsection{1 - Chaptalização}

O Brix da polpa, aferido em refratômetro, foi de $12^{\circ} \mathrm{Brix}$. O passo seguinte foi a chaptalização do mosto para obter uma bebida cujo teor alcoólico estivesse en- tre $10 \%$ e $13 \%(\mathrm{v} / \mathrm{v})$. Para isto foi adicionado, ao volume da polpa, um volume igual de solução de sacarose cuja concentração, em g/L, foi calculada em função de se obter o grau Brix desejado [9, 13 e 38]. Esta solução foi preparada, utilizando-se açúcar cristal, segundo CATALUÑA [13]: cada $25 \mathrm{~g}$ de sacarose adicionados a um volume final de $1 \mathrm{~L}$ elevam o ${ }^{\circ}$ Brix do mosto em, aproximadamente, 2 unidades. No preparo desta, a água foi aquecida a $30^{\circ} \mathrm{C}$ para facilitar a dissolução do dissacarídeo. O grau Brix final no mosto de cajá foi de 24 .

\subsection{2 - Desacidificação e tratamento enzimático}

A partir do valor de $\mathrm{pH}$ do mosto de cajá chaptalizado $(3,3)$, foi feita a correção para facilitar a ação do complexo enzimático utilizado neste trabalho. Após desacidificado com $\mathrm{CaCO}_{3}$, o mosto recebeu tratamento enzimático. Na desacidificação, uma massa do carbonato foi previamente dissolvida em $500 \mathrm{~mL}$ do próprio mosto e, então, adicionado ao volume total a ser fermentado. Este processo foi repetido até o $\mathrm{pH}$ do mosto atingir o valor 3,8, obtido pela leitura em potenciômetro digital (Micronal, B-474). Sendo a polpa de cajá excessivamente viscosa, foi realizado o tratamento enzimático com a adição de Ultrazym ${ }^{R}$ AFP-L (Novo Nordisk Ferment Ltd, Dinamarca). Esta solução é composta de 2 classes de enzimas, poligalacturonases (E.C.3.2.1.15) e celulases (E.C.3.2.1.4), sendo indicada para o tratamento de polpas de frutas, facilitando a clarificação da bebida. A concentração utilizada foi a sugerida pelo fabricante [31] (Tabela 1), adicionada após as correções de acidez e temperatura. Em testes preliminares, foi observado que o complexo enzimático diminuiu a viscosidade do mosto (Figura 1) em função do pH (em pH 3,3 não atuou; em pH 3,8 e 4,5 atuou, não havendo, entretanto, diferenças significativas entre estes dois últimos valores de $\mathrm{pH}$ ).

TABELA 1. Concentração de Ultrazym ${ }^{R}$ AFP-L a ser utilizada no mosto em função da temperatura e tempo de atuação.

\begin{tabular}{llll}
$\begin{array}{l}\text { Faixa de temperatura } \\
\left(\begin{array}{l}\left.{ }^{\circ} \mathrm{C}\right) \\
(\mathrm{ml} / \mathrm{Kg})\end{array}\right.\end{array}$ & AFP-L & Tempo de ação (horas) & Faixa de $\mathrm{pH}$ \\
\hline $20-30$ & $0,5-0,7$ & 8 (pelo menos) & $4,5 \pm 0,5$ \\
$40-50$ & $0,3-0,5$ & 2 & \\
\hline
\end{tabular}

Fonte: Novo DK [31].

\subsection{3 - Sulfitação}

$\mathrm{O} \mathrm{SO}_{2}$ foi adicionado ao mosto na forma de metabissulfito de potássio $\left(\mathrm{K}_{2} \mathrm{~S}_{2} \mathrm{O}_{5}\right)$, um sal cristalino que, na prática, rende $50 \%$ de seu peso em dióxido de enxofre. A concentração máxima de $\mathrm{SO}_{2}$ total no vinho, permitida por lei, é de $350 \mathrm{mg} / \mathrm{L}$ [10]. A concentração no mosto foi $100 \mathrm{mg}$ de $\mathrm{SO}_{2} / \mathrm{L}$, ou $200 \mathrm{mg}$ de $\mathrm{K}_{2} \mathrm{~S}_{2} \mathrm{O}_{5} / \mathrm{L}$ de mosto. Esta massa de metabissulfito foi diluida em $500 \mathrm{~mL}$ de mosto e adicionada de uma só vez à dorna, logo após a correção do pH.

\subsection{4 - Colagem}

A bentonite foi adicionada ao mosto na concentração de $1 \mathrm{~g} / \mathrm{L}$, segundo VOGT et al. [44], a partir de uma 
solução estoque a 10\% em água destilada. A solução foi adicionada ao mosto no início da fermentação, permanecendo durante todo o processo fermentativo. Feita a colagem, a dorna foi levada à estufa para estabilização da temperatura a $22^{\circ} \mathrm{C}$.

\section{3 - Preparo do inóculo e fermentação do mosto}

Utilizou-se uma linhagem selvagem, isolada e pura, de Saccharomyces cerevisiae pertencente a coleção do Laboratório de Microbiologia do Departamento de Biologia da UFLA, codificada como RL-11. A levedura RL-11 foi utilizada em função de resultados obtidos previamente, onde foi avaliada a atividade fermentativa desta levedura e outras 2 leveduras comerciais recomendadas para a elaboração de bebidas alcoólicas. Para atingir a população inicial de $10^{7}$ células $/ \mathrm{mL}$, a levedura foi primeiramente purificada. Partindo-se de uma aliquota da cultura pura, estocada em glicerol a $15 \%$ [24], a $-20^{\circ} \mathrm{C}$, a levedura foi inoculada em $2,0 \mathrm{~mL}$ de meio YW líquido (em g/ L: extrato de levedura, 3,0; extrato de malte, 3,0; peptona universal, 5,0; glicose, 10,0), acidificado com HCL 0,1M até atingir $\mathrm{pH} 3,5$. Depois de incubada a $30^{\circ} \mathrm{C}$ por $24 \mathrm{~h}$, uma nova aliquota da cultura foi transferida para placas de Petri com meio YW sólido (idem ao liquido, acrescentando-se ágar a $12 \mathrm{~g} / \mathrm{L}$ ) a $\mathrm{pH} 3,5$ e adicionado de ampicilina a $30 \mu \mathrm{L} / \mathrm{L}(30 \mathrm{ppm})$. As placas foram incubadas a $30^{\circ} \mathrm{C}$ por $24 \mathrm{~h}$. Da cultura purificada, tomou-se uma aliquota para iniciar a formação do inóculo. Nesta fase, a levedura cresceu em $120 \mathrm{~mL}$, em frascos erlenmeyer, de meio MF, segundo SCHWAN \& ROSE [40], constituído de (em g/L): glicose, 10,0; $\mathrm{KH}_{2} \mathrm{PO}_{4}, 4,5$; $\left(\mathrm{NH}_{4}\right)_{2} \mathrm{SO}_{4}, 3,0$; extrato de levedura 1,$0 ; \mathrm{mgSO}_{4} \cdot 7 \mathrm{H}_{2} \mathrm{O}$, 0,250 e $\mathrm{CaCl}_{2}, 0,250 ; \mathrm{pH} 5,0$. Os frascos com a levedura foram incubados em estufa, provida de agitador orbital, a $28^{\circ} \mathrm{C}$ e $30 \mathrm{rpm}$. O meio foi renovado a cada $24 \mathrm{~h}$ até que a população de $10^{7}$ células $/ \mathrm{mL}$ (para os 20L de mosto a fermentar), verificada por contagem em câmara de Neubauer [6], fosse atingida.

Após o preparo e as devidas correções terem sido feitas, bem como a inoculação, a dorna de inox foi coberta com lâminas de papel aluminio e os 20L de mosto,

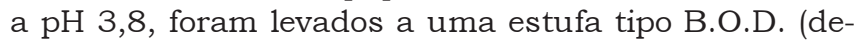
manda bioquímica de oxigênio) cuja temperatura foi estabilizada a $22^{\circ} \mathrm{C}$. A cada dia da fermentação, foi coletada uma amostra do mosto para contagem de células e determinação do grau Brix. Também foi observado o vigor da fermentação em função da liberação de $\mathrm{CO}_{2}$. O final da fermentação foi determinado pela estabilização do valor do ${ }^{\circ}$ Brix.

\section{4 - Trasfega}

Ao final da fermentação, a temperatura da B.O.D. foi regulada para $10^{\circ} \mathrm{C}$, para facilitar a sedimentação do material sólido. Depois de 10 dias a esta temperatura, foi feita uma trasfega na bebida, com aeração [38]. Após esta primeira trasfega, a bebida foi recolocada à temperatura de $10^{\circ} \mathrm{C}$ por mais 30 dias. Ao final destes 30 dias, foi feita a segunda trasfega, sem aeração. A bebida ficou mais 10 dias à temperatura de $10^{\circ} \mathrm{C}$ antes de ser filtrada.

\section{5 - Filtração e atesto}

Após a segunda trasfega e findos os últimos 10 dias da bebida à temperatura de $10^{\circ} \mathrm{C}$, a mesma foi filtrada sob vácuo em frasco tipo Kitassato, de 4L, onde foi acoplado um funil tipo Büchner. Para a filtração foi utilizado, primeiramente, filtro de celulose. Após a primeira filtração, a bebida foi submetida à filtração com terra de diatomácea entremeada a filtros de celulose. Terminada a filtração, a bebida foi acondicionada em garrafões de vidro com capacidade para $5 \mathrm{~L}$ e armazenada a $12^{\circ} \mathrm{C}$, em B.O.D. Um litro da bebida foi reservado para as análises quimicas posteriores.

$\mathrm{O}$ atesto foi feito pelo preenchimento total da capacidade do garrafão, minimizando a quantidade de oxigênio. A presença deste agente oxidante poderia levar à formação de defeitos na bebida, como o avinagramento [34].

\section{6 - Análises químicas da bebida}

Alguns parâmetros foram analisados no fermentado de cajá com a finalidade de avaliar teores que poderiam contribuir para qualificar ou desqualificar a bebida em um posterior teste organoléptico. Como não há uma legislação exclusiva para bebidas de frutas tropicais e a lei que trata de 'fermentado de fruta' [8] relata apenas os atributos graduação alcoólica e chaptalização, os parâmetros aqui analisados foram, em grande parte, comparados àqueles existentes para o vinho.

\subsection{1 - Grau alcoólico ( $\left.{ }^{\circ} \mathrm{GL}\right)$, acidez total, acidez volátil e dióxido de enxofre livre}

Os valores destes parâmetros foram determinados segundo metodologia proposta pelo Ministério da Agricultura [11].

\subsection{2 - Álcoois (etanol e glicerol), carboidratos (sacarose, glicose e frutose) e ácidos orgânicos (acético, lático, málico, succínico, cítrico e tartárico)}

Para as análises cromatográficas, as amostras foram tratadas do seguinte modo: retiradas do refrigerador a $10^{\circ} \mathrm{C}$ e colocadas a temperatura ambiente por, aproximadamente, $4 \mathrm{~h}$ antes da análise em CLAE. Depois de estabilizada a temperatura, $100 \mu \mathrm{L}$ das amostras foram diluídos 100 vezes, em água mili-Q, e filtradas em membrana ultrafiltrante (nitrato-celulose) de porosidade $0,20 \mu \mathrm{m}$, marca Sartorius. Foram utilizados $20 \mu \mathrm{L}$ da amostra para a corrida cromatográfica, injetados manualmente.

Os valores dos parâmetros foram determinados por cromatografia liquida de alta eficiência utilizando-se metodologia modificada a partir de SCHWAN et al. [39] e SHIMADZU [41]. Foi utilizado um cromatógrafo de fase liquida Shimadzu, modelo LC-10Ai (Shimadzu Corp. , Japão), equipado com detectores de índice de refração, modelo RID-10A, e de ultravioleta, modelo SPD-10Ai. A coluna utilizada foi de troca catiônica (poliestireno divinilbenzeno), modelo Shim-pack SCR-101H de 30cm de comprimento e $7,9 \mathrm{~mm}$ de diâmetro (Shimadzu). 
Para a determinação de carboidratos e álcoois, a coluna operou à temperatura ambiente, tendo como fase móvel o ácido perclórico na concentração $100 \mathrm{mM}$ a um fluxo de $0,8 \mathrm{~mL} / \mathrm{min}$. Os compostos foram detectados através do detector de indice de refração.

Para a determinação dos ácidos orgânicos, a coluna operou à temperatura de $50^{\circ} \mathrm{C}$, a fase móvel também foi ácido perclórico $100 \mathrm{mM}$ a um fluxo de $1,0 \mathrm{~mL} / \mathrm{min}$ operando à temperatura ambiente. Neste caso utilizou-se o detector de ultra-violeta, com comprimento de onda selecionado em $210 \eta \mathrm{m}$.

A quantificação foi realizada a partir da comparação com curvas de calibração, determinadas utilizando-se padrões certificados da marca Supelco.

\subsection{3 - Álcoois superiores (propanol, isobutanol, butanol, isoamílico, amílico e hexanol), acetaldeído, metanol e ésteres (acetato de etila e acetato de metila)}

Os teores destes compostos foram determinados por cromatografia gasosa utilizando-se uma metodologia modificada a partir de BOSCOLO et al. [7]. Para as análises, $100 \mu \mathrm{L}$ das amostras (não destiladas) foram diluídos 20 vezes, em água mili-Q, e filtrados em membrana ultrafiltrante (nitrato-celulose) de porosidade $0,20 \mu \mathrm{m}$, marca Sartorius. Foi utilizado $1,0 \mu \mathrm{L}$ da amostra para a corrida cromatográfica. Antes da injeção, $50 \mu \mathrm{L}$ de 4-metilpentan-2-ol (10g/L em etanol 40\%) foram adicionados às amostras como padrão interno. O cromatógrafo utilizado foi da marca Chromopack, modelo 511, equipado com detector de chama ionizada. As condições da corrida foram as seguintes: detector e injetor operando a $250^{\circ} \mathrm{C}$, coluna capilar de silica Carbowax $57 \mathrm{CB}$ de $50 \mathrm{~m}$ de comprimento e $0,22 \mathrm{~mm}$ de diâmetro interno operando em gradiente de temperatura, como segue: $55^{\circ} \mathrm{C}$ durante $5 \mathrm{~min}$; elevação de $2^{\circ} \mathrm{C} / \mathrm{min}$ até chegar aos $100^{\circ} \mathrm{C}$; $100^{\circ} \mathrm{C}$ por $3 \mathrm{~min}$; elevação de $5^{\circ} \mathrm{C} / \mathrm{min}$ até a temperatura de $190^{\circ} \mathrm{C} ; 190^{\circ} \mathrm{C}$ durante $30 \mathrm{~min}$; elevação de $5^{\circ} \mathrm{C} /$ min até a temperatura de $220^{\circ} \mathrm{C} ; 220^{\circ} \mathrm{C}$ durante $15 \mathrm{~min}$, tendo como gás carreador o hidrogênio a um fluxo de $1,2 \mathrm{~mL} / \mathrm{min}$.

\subsection{4 - Potencial hidrogeniônico (pH)}

$\mathrm{O} \mathrm{pH}$ da amostra foi determinado diretamente, segundo INSTITUTO ADOLFO LUTZ [21].

\section{7 - Análise sensorial da bebida}

\subsection{1 - Seleção dos provadores}

Para a execução dos testes de aceitabilidade da bebida, foram selecionados 45 provadores não treinados. Para a seleção, foi feita uma triagem onde os provadores foram questionados quanto a gostar ou não desgostar de bebidas alcoólicas secas (cujo teor de açúcares é inferior a $5 \mathrm{~g} / \mathrm{L}$ ). Os provadores que constituíram o grupo dos que não gostavam de bebida seca não participaram da análise. O corpo de provadores constituiu-se de alunos e professores das instituições Centro Universitário de Lavras (Unilavras/UEMG) e Universidade Federal de
Lavras (UFLA), com faixa etária entre 18 e 58 anos, de ambos os sexos.

\subsection{2 - Degustação}

Cada um dos provadores provou $20 \mathrm{~mL}$ da bebida. A amostra foi servida à temperatura de $10^{\circ} \mathrm{C}$ aproximadamente, às 10.30 horas, em taça transparente, tipo champanha, descartável. Para a amostra, os provadores preencheram uma ficha de avaliação na forma de escala hedônica de 9 pontos [29]. Em um primeiro julgamento, os provadores avaliaram os atributos separadamente (aparência, aroma e sabor). O segundo julgamento foi em relação à aceitação global da bebida.

\subsection{3 - Análise estatística}

A análise estatística da aceitação do fermentado de cajá foi feita a partir dos testes de Mann-Whitney e Chernoff, ambos não paramétricos, utilizando-se o programa Statistica [42].

\section{3 - RESULTADOS E DISCUSSÃO}

\section{1 - Caracterização química das polpas}

As polpas de cajá foram retiradas por despolpadeiras mecânicas e quimicamente caracterizadas antes de iniciar o processo de fermentação. A média dos resultados, obtida em triplicata, encontra-se na Tabela 2. A polpa de cajá apresentou valor médio de $\mathrm{pH}$ de 3,3, o que a caracterizou como uma fruta ácida. A concentração de açúcares em torno de $9,4 \%$ permitiu ser comparada a outras frutas tropicais também com potencial para utilização na indústria de bebidas $[1,15,30]$. A presença de pectinases endógenas é relativamente comum em frutas, conforme já descrito por GRASSIN \& FAUQUENBERGUE [19]. Entretanto, a atividade das poligacturonases naturais presentes na polpa de cajá foi pequena $(19,32$ UAE - Tabela 2), não sendo suficiente, portanto, para contribuir com a redução da viscosidade da mesma, sendo necessária a adição do complexo enzimático.

TABELA 2. Caracterização fĩsico-química da polpa de cajá.

\begin{tabular}{ll}
\hline Características & Color ação externa amarela \\
\hline Peso total (g) & 20,0 \\
Polpa + casca (\%) & 81,6 \\
Semente (\%) & 18,4 \\
Comprimento (mm) & 44,0 \\
Diâmetro (mm) & 33,0 \\
Sólidos solúveis ( ${ }^{\circ B r i x)}$ & 12,3 \\
Acidez total titulável (g/L em ácido málico) & 1,0 \\
Sólidos solúveis/acidez & 12,3 \\
pH & 3,3 \\
Açúcares totais (\%) & 9,4 \\
Açúcares redutores (\%) & 8,0 \\
Amido total (\%) & 0,5 \\
Pectina total(\%) & 0,3 \\
Pectina solúvel(\%) & 0,07 \\
Pectina fracionada (\% em relação aos S.I.A) & 9,8 (A.M) 2,1 (B.M) 2,21 (Prot.) \\
Pectinam etilesterase (UAE) & 378,31 \\
Poligalacturonase (UAE) & 19,32 \\
Vitamina C total (mg/100g) & 34,86 \\
Fenólicos solúveis em água (\%) & 0,12 \\
Fenólicos solúveis em metanol (\%) & 0,11 \\
Fenólicos Solúveis em Metanol 50\% (\%) & 0,14 \\
\hline
\end{tabular}

S.I.A. = sólidos insolúveis em álcool; A.M. = alta metoxilação; B.M. = baixa metoxilação; S.I.A. = solidos insoluveis em álcool; A.M. = alta metoxilação; B.M. $=$
U.A.E. = unidade de atividade enzimática e Prot. = protopectina. 


\section{2 - Preparo e correções no mosto}

A Tabela 3 mostra a correção com sacarose feita no mosto de cajá. O valor do ${ }^{\circ}$ Brix final, obtido no mosto de cajá após a correção, é concordante com os descritos por CATALUÑA [13] e RIZZON et al. [38]. Notou-se, porém, uma ligeira diferença quando comparados os valores de grau alcoólico final da bebida em função do ${ }^{\circ}$ Brix inicial, sendo observado um rendimento de $50 \%$ do teor de sólidos solúveis ( ${ }^{\circ} \mathrm{Brix}$ ), contra valores teóricos de $60 \%$, descritos por CATALUÑA [13] e HASHIZUME [20], a partir de mostos de uva.

TABELA 3. Utilização de sacarose para chaptalização do mosto de cajá.

\begin{tabular}{ccccccc}
\hline Fruta & $\begin{array}{c}\text { 'Brix da } \\
\text { polpa }\end{array}$ & $\begin{array}{c}\text { Volume } \\
\text { de polpa }\end{array}$ & $\begin{array}{c}\text { Gramas de sacarose } \\
\text { adicionada por L de mosto }\end{array}$ & $\begin{array}{c}\text { Volume de } \\
\text { mosto }\end{array}$ & $\begin{array}{c}\text { 'Brix do } \\
\text { mosto }\end{array}$ & $\begin{array}{c}\text { Grau alcoólico } \\
\text { da bebida ( }\end{array}$ \\
\hline Cajá & 12 & $10 \mathrm{~L}$ & 450 & $20 \mathrm{~L}$ & 24 & 12,0 \\
\hline
\end{tabular}

A concentração de açúcares totais encontradas em frutas é bastante variada, e.g. a uva apresenta em média $250 \mathrm{~g} / \mathrm{L}$ de açúcares na sua composição [44]. A polpa de cajá avaliada neste trabalho apresentou valores de 94,1g/L (Tabela 2). De modo geral a concentração de açúcares está relacionada ao cultivar avaliado e ao estádio de maturação do mesmo.

Como a determinação do ${ }^{\circ}$ Brix refratométrico indica sólidos solúveis, não necessariamente constituídos de açúcares na sua totalidade, os valores obtidos para cajá inferem que no grau Brix inicial estão substâncias não fermentesciveis, as quais, como já comentado, podem ter diminuído o rendimento alcoólico final da bebida.

\subsection{1 - Desacidificação e tratamento enzimático}

Na elaboração do fermentado de cajá, o tratamento enzimático do mosto foi feito para clarificar a bebida, o que favorece o aspecto visual. A Figura 1 mostra volumes de mosto de cajá onde uma parcela sofreu tratamento enzimático e a outra parcela não sofreu, antes do início da fermentação, sob temperatura de $22^{\circ} \mathrm{C}$ durante 8 horas. A atividade do complexo enzimático Ultrazym $^{R}$ AFP-L proporcionou uma clarificação do mosto tratado. GÓMEZ-RUIZ et al. [18], obtiveram resultados semelhantes no aspecto visual de sucos de maçã tratados com endopoligalacturonases (pectinases). O tratamento enzimático favoreceu o processo de clarificação do fermentado de cajá.

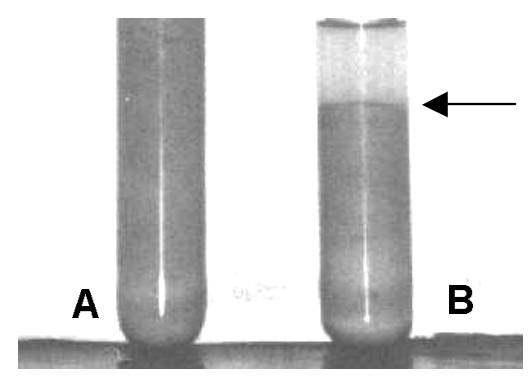

FIGURA 1. Tratamento enzimático do mosto de cajá em pH 3,8. A) Polpa de cajá sem enzima e B) Polpa de cajá com enzima Ultrazym AFP-L.

\subsection{2 - Sulfitação}

A concentração utilizada foi de $100 \mathrm{mg}$ de $\mathrm{SO}_{2}$ por $\mathrm{L}$ de mosto $(10 \mathrm{~g} / \mathrm{hL})$, cerca de $200 \mathrm{mg}$ de $\mathrm{K}_{2} \mathrm{~S}_{2} \mathrm{O}_{5}$. Estes valores, considerados elevados para iniciar a fermentação, foram adotados pois, segundo HASHIZUME [20], a depender do valor do $\mathrm{pH}$ do mosto, a quantidade de $\mathrm{SO}_{2}$ deve ser alterada, sendo necessário mais $\mathrm{SO}_{2}$ a $\mathrm{pH}$ mais elevado, e.g. 3, $\mathrm{Og}$ de $\mathrm{SO}_{2} / \mathrm{hL}$ a pH 3,0 e $2 \mathrm{Og} \mathrm{de} \mathrm{SO}_{2} / \mathrm{hL}$ a $\mathrm{pH} 3,8$. Como o mosto de cajá teve seu valor de $\mathrm{pH}$ corrigido para 3,8, o teor inicial de metabissulfito de potássio $\left(\mathrm{K}_{2} \mathrm{~S}_{2} \mathrm{O}_{5}\right)$ utilizado foi superior aqueles preconizados por OUGH [33], que cita concentrações entre $6 \mathrm{~g} / \mathrm{hL}$ e $8 \mathrm{~g} / \mathrm{hL}$, porém não proporcionais aos descritos por HASHIZUME [20].

Em função da concentração utilizada, foi observado um atraso no início da fermentação de cerca de 12 horas (em função da não produção de $\mathrm{CO}_{2}$ ), concordando com o que foi descrito por GERBAUX e MEURGUES [16]. Estes autores obtiveram um atraso no início da fermentação quando trataram o mosto de uvas com concentrações de $\mathrm{SO}_{2}$ superiores a $80 \mathrm{mg} / \mathrm{L}$. Também foi observado que após o início da fermentação, o transcurso da mesma não foi afetado, o que mostrou resultados concernentes aos apontamentos também feitos pelos autores supracitados.

Nesta concentração utilizada, $100 \mathrm{mg} / \mathrm{L}$, o $\mathrm{SO}_{2}$ mostrou uma eficiência no controle microbiano. Durante as contagens de células, no periodo de fermentação, não foi observada a presença de bactérias. Uma outra evidência da ausência de contaminação, neste caso pelas bactérias do ácido lático, foi a não detecção de ácido lático e a presença de ácido málico no fermentado de cajá nas análises feitas em CLAE (cromatografia líquida de alta eficiência). Estes resultados fazem concluir que o $\mathrm{SO}_{2}$ mostrou-se eficiente nas condições testadas.

\subsection{3 - Colagem}

A bentonite utilizada partiu de uma solução aquosa na concentração de $10 \%$, o que facilitou a dispersão da argila no mosto a fermentar. O principal efeito da bentonite é a precipitação do material protéico por adsorção e neutralização de cargas (as bentonites possuem cargas negativas, neutralizando as positivas), sendo que neste aspecto ela atua desnaturando enzimas oxidativas, como observado por MANFREDINI [25]. A bentonite também possui uma ação física, pois à medida que vai sedimentando carrega consigo as partículas suspensas.

A bentonite introduzida ao mosto de cajá na fase pré-fermentativa proporcionou uma melhor clarificação da bebida por facilitar a sedimentação da parte sólida do mosto, tornando mais fáceis as etapas posteriores de trasfega e a filtração.

\section{3 - Preparo do inóculo e fermentação do mosto: elaboração da bebida}

No decorrer da elaboração do fermentado de cajá, vários procedimentos foram realizados para adequação da metodologia para a referida fruta. O fluxograma re- 
presentado na Figura 2 mostra as diferentes etapas a que foi submetido o mosto da fruta até a formação do produto final.

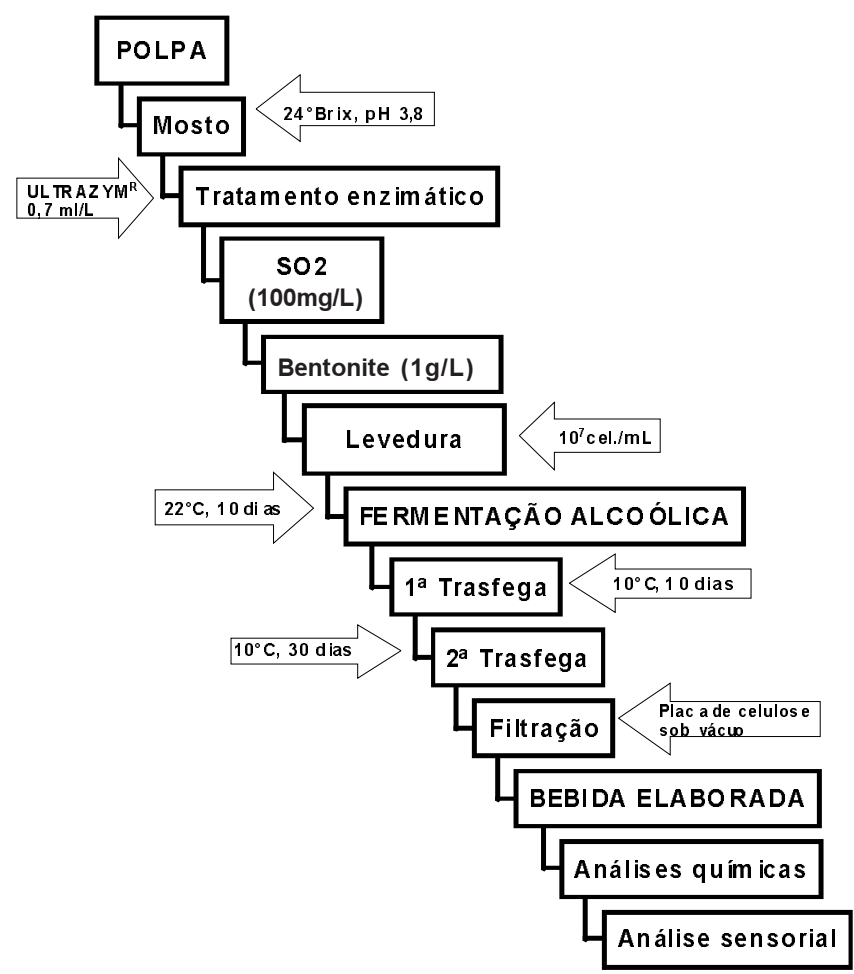

FIGURA 2. Fluxograma do processo de elaboração do fermentado de cajá.

O inóculo empregado, Saccharomyces cerevisiae RL11 , rendeu um número de células $/ \mathrm{mL}$ próximo de $10^{7}$, ideal para iniciar uma fermentação, segundo AMERINE \& CRUESS [2] e PATO [34]. Além disso, mostrou ser eficiente uma vez que a concentração de etanol após 10 dias de fermentação foi próximo de $9,6 \% \mathrm{~m} / \mathrm{v}(12 \% \mathrm{v} / \mathrm{v})$. Estes resultados podem ser comparados com os obtidos por OLIVEIRA et al. [32], que encontraram uma valor de $7,5 \% \mathrm{~m} / \mathrm{v}$ quando fermentando polpa de pupunha com ${ }^{\circ}$ Brix inicial de 24.

\section{4 - Análises químicas da bebida}

As análises químicas realizadas no fermentado de cajá mostraram resultados próximos àqueles estabelecidos para vinhos de mesa do tipo seco (Tabela 4). Apesar de serem frutas bem diferentes, os indices utilizados para a qualificação da bebida estão muito envolvidos com os cuidados tomados durante o processo de elaboração da mesma, apontando que dentro das condições tratadas no trabalho os resultados foram satisfatórios em relação à metodologia proposta.

A análise de açúcares totais por cromatografia líquida de alta eficiência não detectou presença de sacarose, glicose ou frutose. Estes resultados concordam com PATO [34] e OUGH [33]. Segundo estes autores, se a fermentação for conduzida até o final, sem ser interrompida e sem que haja chaptalização durante o processo, os açú- cares presentes no mosto serão convertidos a etanol e outros compostos. Não foi detectada a presença de metanol nem no mosto e nem no produto final.

TABELA 4. Valores analíticos encontrados no fermentado de cajá e valores legais estabelecidos para vinho

\begin{tabular}{llll}
\hline Índices para vinhos de mesa & Máximo & $\begin{array}{c}\text { Limites } \\
\text { Mínimo }\end{array}$ & $\begin{array}{r}\text { Valores obtidos no } \\
\text { fermentado de cajá }\end{array}$ \\
\hline Álcool etílico $\left({ }^{\circ} \mathrm{GL}\right)$ & 13,0 & 10,0 & 12,0 \\
Álcool metílico $(\mathrm{g} / \mathrm{L})$ & 0,35 & - & 0,0 \\
Acidez total $(\mathrm{meq} / \mathrm{L})$ & 130,0 & 55,0 & 29,0 \\
Acidez volátil $(\mathrm{meq} / \mathrm{L})$ & 20,0 & - & 5,5 \\
Sulfatos totais, em $\mathrm{K}_{2} \mathrm{SO}_{4}(\mathrm{~g} / \mathrm{L})$ & 1,0 & - & na \\
Cloretos totais, em $\mathrm{NaCl}(\mathrm{g} / \mathrm{L})$ & 0,20 & - & na \\
Anidrido sulfuroso $\left(\mathrm{SO}_{2}\right)$ total $(\mathrm{g} / \mathrm{L})$ & 0,35 & - & na \\
Açúcares totais: & & - & \\
$\quad$ Vinho seco & 5,0 & - & 0,0 \\
\multicolumn{1}{c}{ Vinho meio seco } & 20,0 & 4,0 & - \\
$\quad$ Vinho suave ou doce & - & 20,1 & - \\
& & & $\mathrm{pH}=3,5$ \\
\hline
\end{tabular}

* Fonte: BRASIL [10]. na = parâmetro não avaliado.

A Tabela 5 apresenta alguns compostos, exceto metanol, que caracterizam o sabor e o aroma de bebidas fermentadas, analisados por cromatografia liquida de alta eficiência e por cromatografia gasosa. Os valores de álcoois superiores totais encontrados para o fermentado de cajá, cerca de $0,7 \mathrm{~g} / \mathrm{L}$, mostraram-se superiores aos valores médios para vinho citados por VOGT et al. [44], que variam entre $0,1 \mathrm{~g} / \mathrm{L}$ e $0,3 \mathrm{~g} / \mathrm{L}$.

É necessário lembrar que as polpas de cajá foram diluídas em igual volume de solução de sacarose, o que pode ter diminuído a concentração dos compostos formadores de aroma e alterado o sabor da bebida. A concentração de acetaldeído (Tabela 5), não detectada na análise por cromatografia gasosa pode ter sido função do elevado $\mathrm{pH}$ do mosto, 3,8, como observado também por CLETO [14]. O acetaldeído pode ser formado, também, pela oxidação do mosto em função da aeração excessiva, um cuidado tomado durante a estabilização da bebida.

TABELA 5. Concentração de compostos voláteis e não voláteis encontrados no fermentado de cajá. As determinações foram realizadas por CG e CLAE.

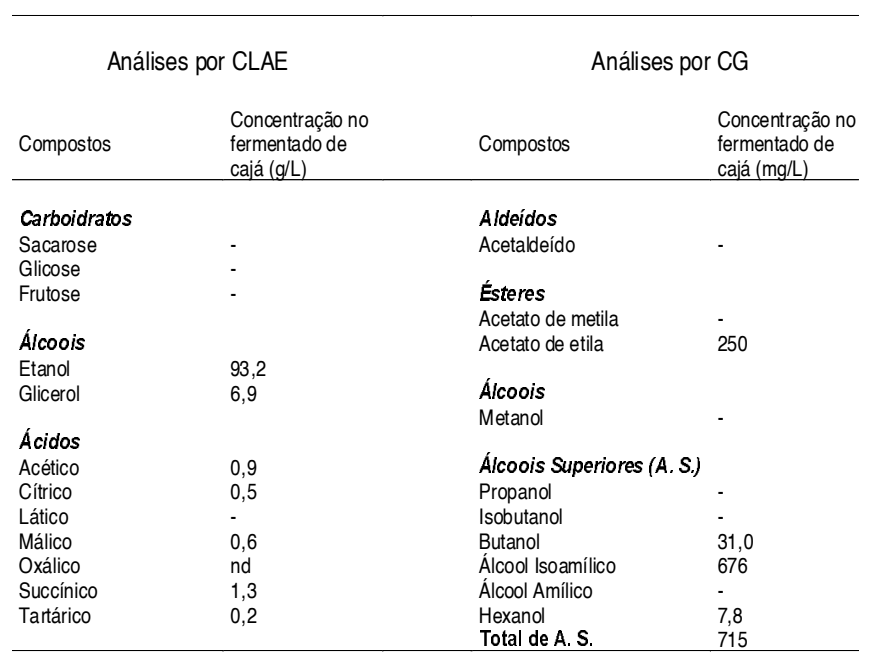

Observação: - não detectado. 
O valor de acetato de etila encontrado (Tabela 5) supera o valor descrito por BERRY e WATSON [5] como sendo limite para a sensibilidade em testes organolépticos. CLETO [14] encontrou valores semelhantes de acetato de etila em fermentados de cana-de-açúcar, laranja e uva, antes de promover a destilação dos mesmos.

Como pode ser observado na Tabela 5, não foram detectados açúcares no fermentado de cajá, o que o caracteriza como bebida seca [10]. A concentração de glicerol, cerca de $6 \mathrm{~g} / \mathrm{L}$, está com valor próximo de conferir corpo e textura à bebida, segundo VOGT et al. [44], que citam valores entre 6g/L e 10g/L. A Figura 3 apresenta o cromatograma do fermentado de cajá, onde pode ser observada, entre vários compostos, a alta concentração de álcool isoamílico, cerca de $676 \mathrm{mg} / \mathrm{L}$, um álcool derivado do metabolismo da leucina.

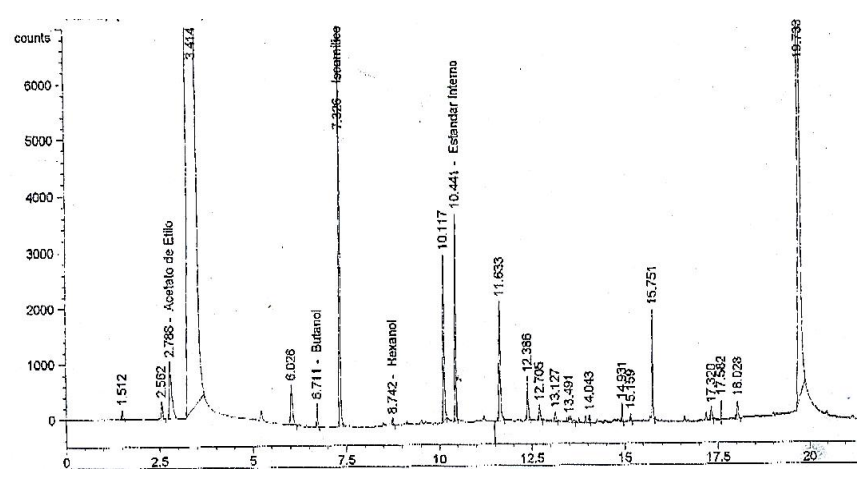

FIGURA 3. Cromatograma de compostos presentes no fermentado de cajá analisados por cromatografia gasosa. Acetato de etila, butanol, álcool isoamílico e hexanol apresentaram, respectivamente, as seguintes concentrações e tempos de retenção: 250mg/L e 2,7 min; 31,0mg/L e 6,7 min; 676mg/ L e 7,3 min; 7,8mg/L e 8,7 min. Os demais picos, presentes na amostra, não foram identificados.

\section{5 - Análise sensorial da bebida}

Após as análises químicas, a bebida elaborada foi submetida à análise sensorial para verificar sua aceitação junto ao público. A Tabela 6 apresenta as notas atribuídas à bebida, assinaladas na escala hedônica de 9 pontos. Pode ser observado a maior média para o atributo aroma, certamente devido as altas concentrações de compostos formadores de aroma, como álcoois superiores e ésteres (Tabela 5). O valor relativo à aparência, média 8, na Tabela 6, pode ser justificado pela limpidez e cor da bebida. O sabor da bebida obteve a menor média, 7, o que refletiu que os provadores 'gostaram moderadamente' da bebida. Quando considerada no aspecto geral, a bebida apresentou um índice bom, próximo a 'gostar muito'.

A expressão percentual de aceitação e não aceitação da bebida está apresentada na Tabela 7 , em função das notas atribuidas pelos provadores. Pode-se observar que em relação a aparência e ao aroma, nenhum dos provadores desgostou da bebida e o percentual de aceitação (pelo menos 'gostaram muito') foi o mesmo, 87\%. Em relação ao sabor, houve aceitação por apenas 40\% dos provadores. Neste mesmo atributo, cerca de $7 \%$ dos provadores desgostaram do fermentado de cajá. Uma das possiveis inferências em relação a não aceitação da bebida foi o desconhecimento da fruta por parte dos provadores. A Tabela 7 mostra que, em relação aos aspectos gerais, $51 \%$ dos provadores gostaram muito da bebida.

TABELA 6. Freqüência e médias das notas para os atributos de análise sensorial para o fermentado de cajá (Teste de Mann-Whitney)

\begin{tabular}{|c|c|c|c|c|c|c|c|c|c|c|}
\hline \multicolumn{11}{|c|}{ Fermentado de Cajá } \\
\hline Atributos & 1 & 2 & 3 & 4 & 5 & 6 & 7 & 8 & 9 & Média (valor aproximado) \\
\hline Aparência & & & & & 1 & 1 & 4 & 24 & 15 & 8 \\
\hline Aroma & & & & & & 3 & 3 & 16 & 23 & 8 \\
\hline $\begin{array}{l}\text { Sabor } \\
\text { Aspectos }\end{array}$ & & & 2 & 1 & 1 & 8 & 15 & 13 & 5 & 7 \\
\hline Gerais & & & & & & 5 & 17 & 17 & 6 & 8 \\
\hline
\end{tabular}

Onde: 1 = desgostei extremamente; 9 = gostei extremamente

TABELA 7. Percentagem de aceitação e recusa do fermentado de cajá conforme análise de escala hedônica de 9 pontos respondida por 45 provadores não treinados.

\begin{tabular}{lcc}
\hline Atributo & \% de notas de 1 a 4 (Recusa) & $\%$ de notas de 8 a 9 (Aceitação) \\
\hline Aparência & $0,0 \%$ & $86,7 \%$ \\
Aroma & $0,0 \%$ & $86,7 \%$ \\
Aspectos Gerais & $0,0 \%$ & $51,1 \%$ \\
Sabor & $6,7 \%$ & $40,0 \%$ \\
\hline
\end{tabular}

Um teste não paramétrico, conhecido como faces de Chernoff, foi realizado para constatação da aprovação da bebida pelos provadores (Figura 4). Este teste tornou mais nitidas as diferenças obtidas entre os atributos da bebida por utilizar um reconhecimento visual, não numérico. Os valores atribuídos ao fermentado de cajá foram comparados com uma escala padrão, 'normal', que não expressa valores. As faces confirmaram que a aparência e o aroma foram atributos de muita qualidade desta bebida, seguidos pelos aspectos gerais.

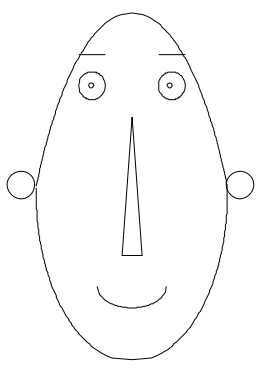

Caja

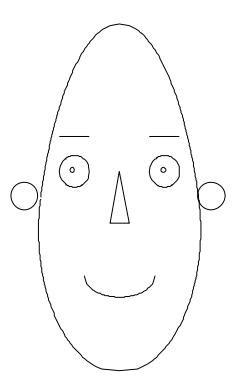

Normal
FIGURA 4. Representação da aceitação do fermentado de cajá através de faces de Chernoff, onde: Aspectos gerais = largura da face; Aroma $=$ comprimento do nariz; Sabor

= curvatura da boca e Aparência = altura dos olhos.

A Figura 5 apresenta a bebida elaborada, após todas as etapas do processo fermentativo e pós-fermentativo. 


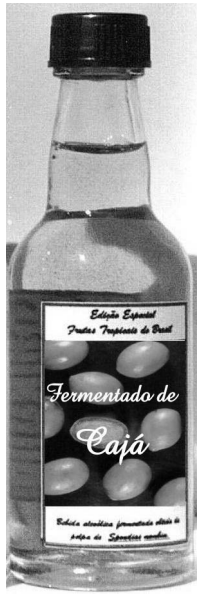

FIGURA 5. Bebida final obtida da fermentação do mosto de polpas de cajá.

\section{4 - CONCLUSÕES}

A partir da metodologia desenvolvida neste trabalho para a elaboração do fermentado de cajá, concluiu-se que os processos normalmente empregados na fabricação de bebidas fermentadas podem ser adaptados para a de cajá. A metodologia obtida foi simples, podendo ser implantada em um espaço físico relativamente pequeno. A diluição das polpas com solução de sacarose, para melhorar a fluidez do mosto diminuiu a concentração dos componentes formadores de aroma da bebida, não interferindo na produção de etanol, visto que as vias de formação seguem rotas distintas. A utilização do complexo enzimático e da solução de bentonite durante todo o processo fermentativo trouxe resultados satisfatórios para a clarificação da bebida. A levedura Saccharomyces cerevisiae RL-11, testada neste trabalho, mostrou-se capaz de fermentar todos os açúcares fermentesciveis do mosto de cajá e também apresentou a característica de floculação. A análise sensorial revelou uma boa aceitação, principalmente ao levar-se em conta o desconhecimento, por parte dos provadores, da fruta que originou a bebida. Observou-se que, a partir da aceitabilidade da bebida, esta tecnologia pode ser uma das alternativas para a utilização do excedente de safras ou um novo ramo para a fruticultura industrial.

\section{5 -REFERÊNCIAS BIBLIOGRÁFICAS}

[1] Alves, R. E.; FIlgueiras, H. A. C.; MOURA, C. F. H. (editores). Caracterização de frutas nativas da América Latina. Jaboticabal: Funep, 2000. v. 9, p. 15-18. (Série Frutas Nativas). Edição comemorativa do $30^{\circ}$ aniversário da Sociedade Brasileira de Fruticultura.

[2] AMERINE, M. A.; CRUESS, W. V. The technology of winemaking. Westport: Avi, 1960. cap. 6, p. 213-302.

[3] ARKCOLL, D. New crops from Brazil. In: JANICK, J.; SIMON, J. E. (eds.). Advances in new crops. Portland: Timber Press, 1990. v. 1 p. 367-371. <URL>http:// www.hort. purdue.edu/newcrop/proceedings 1990/ V1-367.html. Arquivo capturado em 06/10/2000.
[4] ASSOCIATION OF OFFICIAL ANALYTICAL CHEMISTS Official methods of analyses of A. O. A. C. $15^{\text {th }} \mathrm{ed}$. Washington: AOAC, 1990. v. 2, cap. 37, p. 915 e 922.

[5] BERRY, D. R.; WATSON, D. C. Production of organoleptic compounds. In: BERRY, D. R.; RUSSELL, I.; STEWART, G. G (eds.). Yeast biotechnology. London: Allen \& Unwin, 1987. cap. 11.

[6] BIO-RAD. Pulsed field electrophoresis systems: instructions manual and applications guide. United States of America: Bio-Rad Laboratories, 1992. (Catalog numbers 170-3612 through 170-3729).

[7] Boscolo, M.; BEZERRA, C. W. B.; CARDOSO, D. R. et al. Identification and dosage by HRGC of minor alcohols and esters in Brazilian sugar cane spirit. J. of Braz. Chem. Society, São Paulo, v. 11, n. 1, p. 86-90, 2000.

[8] BRASIL. Leis, Decretos, etc. Decreto n. 2314, de 4 de set. de 1997. Diário Oficial da União, Brasília, n. 171,5 de set. 1997. Seção I, p. 19549. [Regulamenta a lei n. 8918 , de 14 de julho de 1994, que dispõe sobre a padronização, a classificação, o registro, a inspeção, a produção e a fiscalização de bebidas].

[9] BRASIL. Leis, Decretos, etc. Lei n. 7678, de 08 de out. de 1988. Brasília: Ministério da Agricultura e do Abastecimento. [Dispõe sobre a produção, circulação e comercialização do vinho e derivados da uva e do vinho, e dá outras providências]. Disponivel em:<http:// www.agricultura.gov. br/leis.asp?lei=7678>. Acesso em: 09 de fev. de 2001.

[10] BRASIL. Leis, Decretos, etc. Portaria n. 84, de 25 de abr. de 1988, do Min. da Agricultura. Diário Oficial da União, Brasília, de 4 mai. 1988. Seção I, p. 7747-7750. [Aprovar a Norma referente à 'complementação dos Padrões de Identidade e Qualidade do vinho' e da outras providencias].

[11] BRASIL. Ministério da Agricultura. Secretaria Nacional de Defesa Agropecuária - Laboratório Nacional de Referência Vegetal. Metodologias de análise de bebidas e vinagres. Brasília, 1985, n. p.

[12] CAMARgo, U. A. Uvas do Brasil. Bento Gonçalves: EMBRAPA-CNPUV, 1994. 90p. (EMBRAPA-CNPUV. Documentos, 9)

[13] CATALUÑA, E. As uvas e os vinhos. 2.ed. Rio de Janeiro: Globo, 1988. 207p.

[14] CLETO, F. V. G. Ação da lecitina no processo fermentativo, rendimento e composição das aguardentes em mostos de cana-de-açúcar, laranja e uva. Jaboticabal, 2000. 75p. Tese (Doutorado em Microbiologia) - Faculdade de Ciências Agrárias e Veterinárias, Universidade Estadual Paulista (UNESP).

[15] FRANCO, G. Tabela de composição química dos alimentos. 9.ed. São Paulo: Atheneu, 1999. 307p.

[16] GERBAUX, V.; MEURGUES, O. Influence du sulfitage et du débourbage des moûts sur l'élaboration et la qualité des vins de chardonnay. Rev. des CEnologues. France, n. 78, p. 15-18, 1995.

[17] GOMES, R. P. Fruticultura brasileira. 11.ed. São Paulo: Nobel, 1985. $446 \mathrm{p}$.

[18] GOMEZ-RUIZ, L.; GARCIA-GARIBAY, M.; BARZANA, E. Utilization of endo-polygalacturonase from Kluyveromyces fragilis in the clarification of apple juice. J. of Food Sci., Chicago, v. 53, n 4, p. 1236-1237 and 1240, 1988.

[19] GRASSIN, C.; FAUQUEMBERGUE, P. Fruit juices. In: GODFREY, T.; WEST, S. (eds.). Industrial Enzimology. 2.ed. Great Britain: Macmillan Press, 1996. Cap. 2.13 . 
[20] HASHIZUME, T. Fundamentos de tecnologia do vinho. In: AQUARONE, E.; LIMA,U.A.; BORZANI, W. Alimentos e bebidas produzidos por fermentação. 1.ed.4.reimp. São Paulo: Edgard Blücher, 1993. v. 5, cap. 2, p. 14-43.

[21] InstituTo ADOLFO LUTZ. Normas analíticas do Instituto Adolfo Lutz: Métodos químicos e físicos para análises de alimentos. 3.ed. São Paulo, 1985. v. 1, p. 27 .

[22] JEN, J. J; ROBINSON, M. L. Pectinolytic enzymes in sweet bell peppers (Capsicum annuum L). J. of Food Sci., Chicago, v. 49, n. 4, p. 1085-1087, 1984.

[23] JOAS, J. Les mombins: des possibilités technologiques intéressantes. Fruits, [s.1.], v. 37, n. 11, p. 727-729, 1982.

[24] KURTZMAN, C. P. ; FELL, J. W (eds.). The yeasts: a taxonomic study. 4.ed. Amsterdan: Elsevier, 1998. p. 79.

[25] MANFREDINI, M. Coadiuvanti enologici: bentonite. Vignevini, Itália, v. 4, p. 43-46, 1989.

[26] MATSUNO; H., URITANI, I. Physiological behaviour of peroxidase isoenzymes in sweet potato root issue injured by cutting black root. Plant and Cell Physiology, Tokyo, v. 13, p. 1091-1101,1972.

[27] MCCREADY; R. M.; MCCOMB, E. A. Extraction and determination total pectin material in fruits. Anal. Chem., Washington, v. 24, n. 12, p. 1586-1588, Dec. 1952.

[28] MILLER, G. L. use of dinitrosalicylic acid for determination of reducing sugar. Anal. Chem., [s.l.], v. 31, n. 2, p. 426-428, mar. 1959.

[29] MORAES, M. A. C. Métodos para avaliação sensorial dos alimentos. 8.ed. Campinas: Unicamp, 1993. 93p. (Série Manuais).

[30] MORTON, J. Yellow mombin. In: MORTON, J. F. Fruits of warm climates. Miami, 1987. p. 245-248. Disponível em: <http://www.hort.purdue.edu/newcrop/ morton/yellow_mombin_ars.html>. Acesso em: 06 de out. de 2000

[31] NOVO NORDISK FERMENT LTD. Ultrazym AFP-L: a special enzyme preparation for liquefation of fruit. Great Britain, 1998. (Catálogo do fabricante).

[32] OLIVEIRA, L. P. ; MAEDA, R.; ANDRADE, J. de S.; PEREIRA JÚNIOR, N. ; CARVALHO, S. M. da S.; ASTOLFI FILHO, S. Processo fermentativo para produção de bebida alcoólica de pupunha (Bactris gasipaes Kunth). Biotecnol., Ciênc. e Desenvolvimento, n. 19, p. 50-54, 2001.

[33] OUGH, C. S. Tratado Básico de Enología. Tradução de Concepción Llaguno Marchena e María Dolorez Cabezudo Ibañes. Zaragoza: Acribia, 1996. 294p. Tradução de: Winemaking basics. New York: Haworth Press, 1992.

[34] PATO, O. O vinho: sua preparação e conservação. 7 ed. Lisboa: Livraria Clássica Editora, 1982. 433 p. (Coleção Técnica Agrária).
[35] PREssey, R.; AVANTS, J. K. Separation and characterization of the endopolygalacturoase and exopolygalacturonase from peaches. Plant Physiology, Baltimore, v. 52, p. 252-256, 1973.

[36] REICHER, F.; SIERAKOWSKI, M. R.; CORRÊA, J. C. B. Determinação espectrofotométrica de taninos pelo reativo fosfotúngstico fosfomolíbdico. Arq. de Biol. e Tecnologia, Curitiba, v. 24, n. 4, p. 401-411, 1981.

[37] RIZZON, L. A.; MANFROI, V.; MENEGUZZO, J. Elaboração de suco de uva na pequena propriedade vitícola. Bento Gonçalves: EMBRAPA-CNPUV, 1998. 24p. (EMBRAPA-CNPUV. Documentos, 21)

[38] RIZZON, L. A.; ZANUS, M. C.; MANFREDINI, S. Como elaborar vinho de qualidade na pequena propriedade. Bento Gonçalves: EMBRAPA-CNPUV, 1994. 36p. (EMBRAPA-CNPUV. Documentos, 12).

[39] SCHWAN, R. F.; MENDONÇA, A. T.; SILVA JÚNIOR, J. J. et al. Microbiology and physiology of cachaça (aguardente) fermentations. Antonie van Leeuwenhoek Int. J. of Gen. and Mol. Microbiol., Netherlands, v. 79, p. 89-96, 2001.

[40] SCHWAN, R. F.; ROSE, A. H. Polygalacturonase production by Kluyveromyces marxianus: effect of medium composition. J. of Appl. Bact., United Kingdom, v. 76, p. 62-67, 1994.

[41] SHIMADZU. Application data book. Japan: Shimadzu, 1998? 104p. (Catálogo C190-E001).

[42] STATSOFT INC. Statistica for windows [computer program manual]. Tulsa, OK. Statisoft, 1995.

[43] STROHECKER, R; HENNING, H. M. Vitamins assay: tested methods. Stuttgarg: Verlag, 1965. p. 427-251.

[44] VOGT, E.; JAKOB, L.; LEMPERLE, E. et al. El vino: obtención, elaboración y análisis. Tradução de Jaime Esain Escobar. 2.ed. Zaragoza: Acribia, 1986. 294p. Tradução de: Der Wein: bereitung, behandlung, untersuchung. 9 ed. Stuttgart: Eugen Ulmer, 1984.

[45] WISSEMANN, K. W.; LEE, C. Y. Polyphenoloxidase activity during grape maturation and wine production. Am. J. of Enol. and Viticulture, Davis, v. 31, n. 3, p. 206-211, 1980.

[46] YEMN, E. W.; WILLIS, A. J. The estimation of carbohydrates in plant extracts by anthrone. The Biochem. Journal, London, v. 57, p. 508-514, 1954.

\section{6 - AGRADECIMENTOS}

Os autores são gratos à União Européia (ERB IC18 CT97 0182) pelo suporte financeiro do projeto. DRD agradece a Universidade Federal de Lavras (Departamento de Ciência de Alimentos e Departamento de Biologia) pela oportunidade de cursar o mestrado e ao CNPq pelo periodo de bolsa concedida. 